\title{
Educador social: uma identidade a caminho da profissionalização?
}

Gerson Heidrich da Silva UNISA

\section{Resumo}

0 objetivo deste artigo é apresentar uma síntese da pesquisa de mestrado A construção de identidade do educador social na sua prática cotidiana: a pluralidade de um sujeito singular, na qual se buscou conhecer características da identidade que o educador social, de nível universitário, da cidade de São Paulo, vem construindo na sua prática cotidiana. A metodologia desenvolvida para este estudo constou de um instrumento elaborado pelo pesquisador e preenchido, entre início de março e final de setembro de 2006, por quinze educadores sociais de áreas de formação diversas: Psicologia, Serviço Social e Pedagogia. Verificou-se, dessa maneira, o perfil socioeconômico e cultural desses educadores, complementando com aspectos qualitativos de sua prática cotidiana relatada mediante questões semidirigidas e duas cartas propiciadoras de livre expressão. Para a análise, contou-se com a Psicologia Histórico-Cultural e o diálogo com autores da Sociologia, Pedagogia e Serviço Social. Os resultados analisados apontaram a desvalorização, a impotência e a resignação como características marcantes dessa identidade em construção. A precariedade para o desenvolvimento do trabalho e a descontinuidade (principalmente dos Programas de Assistência Social) sustentam a queixa instaurada no discurso desses sujeitos. Constatou-se também certo apelo à necessidade de aprimoramento da formação (especialização, qualificação etc.), o que nos levou a pensar na profissionalização desse educador. Apontou-se, então, a universidade como campo dinâmico de reflexão, discussão, acolhimento e construção de saberes específicos e facilitadores de ressignificação do trabalho desenvolvido. Isso destituiria, assim pensamos, o caráter "missionário" dessa prática como um dos álibis da desesperança.

\section{Palavras-chave}

Identidade - Educador social - Socioeducativo - Subjetividade.

Correspondência: 


\title{
Social educator: an identity on its way to professionalization?
}

Gerson Heidrich da Silva

UNISA

\begin{abstract}
The objective of this article is to present a synthesis of the research carried out during our Master program, which was entitled "The construction of the identity of the social educator in his daily practice: the plurality of a singular subject" [A construção de identidade do educador social na sua prática cotidiana: a pluralidade de um sujeito singular]. The study attempted to understand the features of the identity that the social educator of university-level education has been building in his/her daily practice in the city of São Paulo. The methodology developed for this study included an instrument created by the researcher, and filled out between March and September 2006 by fifteen social educators from different areas of formation: Psychology, Social Service, and Pedagogy. It was then possible to assess the socioeconomic profile of these educators, complementing this information with qualitative aspects of their daily practice gathered from semi-directed questions and two letters aimed at stimulating their free expression. The analysis relied on the framework of Cultural-Historical Psychology and on the dialogue with authors from Sociology, Pedagogy and Social Service. The results analyzed pointed to devaluation, feeling of impotence, and resignation as defining features of this identity under construction. The precariousness of the conditions for the development of their work, and the lack of continuity (especially of the Programs of Social Assistance) give support to the complaint expressed in their discourse. Also noticeable was the mention to the need for improvement of their formation (specialization, qualification etc), leading us to reflect on the professionalization of these educators. The university appeared then as a dynamic field for reflection, discussion, receptiveness, and construction of specific knowledges, conducive of a re-signification of the work developed. This, we believe, would contradict the "missionary" character of this practice as one of the alibis for the lack of hope.
\end{abstract}

Contact:

Gerson Heidrich da Silva

Rua José Antonio Coelho, 575 c. 1

04011-061 - São Paulo - SP

e-mail: psicopiq@uol.com.br

\section{Keywords}

Identity - Social educator - Socio-educative - Subjectivity. 
Este artigo é uma síntese de minha dissertação de mestrado, intitulada $A$ construção de identidade do educador social na sua prática cotidiana: a pluralidade de um sujeito singular (Silva, 2008), a qual tinha como objetivo principal conhecer características de identidade que o educador social, de nível universitário, da cidade de São Paulo, vem construindo na sua prática cotidiana.

Motivado pela experiência da prática inicialmente como educador social e, posteriormente, como gerente e coordenador de programas sociais conveniados com a Prefeitura Municipal de São Paulo como o Programa Fortalecendo a Família - PFF - e o Programa de Assistência Social a Família - PROASF -, passei a questionar o trabalho socioeducativo desenvolvido pelo educador social com a população em situação de risco e exclusão social. Isso porque suas ações, definidas geralmente por políticas sociais homogeneizantes, ao não prezarem as especificidades de um território, de um lugar, de uma comunidade, parecem impor à população atendida a condição de um favor em detrimento de um direito que lhe deve ser assegurado. Assim, o direito passa a ser visto como mérito e exceção (Koga, 2003).

Nesse sentido, essa população, privada de condições básicas para viver com certa dignidade (trabalho, saúde, educação, lazer, saneamento básico etc.), encontra-se em um quadro de humilhação social também vivido e compartilhado, muitas vezes, pelo educador ao se deparar com a falta de condições físicas e materiais para o desenvolvimento do trabalho socioeducativo. Uma humilhação que, segundo Gonçalves Filho (1998), ao se tratar de um fenômeno psicológico e político, gera uma situação de impedimento da humanidade do humilhado, ou seja,

[...] uma situação reconhecível nele mesmo - em seu corpo e gestos, em sua imaginação e em sua voz - e também reconhecível em seu mundo - em seu trabalho e em seu bairro. (p. 3)
A intenção deste artigo é apresentar uma sintese desse processo de construção, o qual, apoiado principalmente na Psicologia Histórico-Cultural de Vygotsky (2003) e em seus comentadores [Oliveira, 1997; Molon, 1999; Kahhale, 2002; entre outros], revelou algumas características da identidade que o educador social vem construindo durante o desenvolvimento do seu trabalho.

Ao consideramos o trabalho socioeducativo como uma metodologia que deveria ser construída na prática cotidiana, defendemos, a partir das discussões e reflexões com as pessoas atendidas, propostas de ações compartilhadas e não a imposição unilateral de práticas a serem desenvolvidas ou simplesmente acatadas, como nos lembra Mioto (2004).

\section{A construção de identidade profissional}

Ao defendermos a ideia de que, qualquer que seja a realidade do sujeito, ele é sempre um ser em construção, acreditamos que a identidade do educador social se construa e seja justamente marcada pelas especificidades e profundas ambiguidades do contexto no qual se insere. Assim, embasamos nosso estudo nas referências teóricas interacionistas, cuja concepção pressupõe a constituição do homem como sujeito a partir de sua relação com o outro, quando inserido em determinado contexto cultural, caracterizando-o, em sua totalidade objetiva e subjetiva, como um ser ativo, social e histórico (Bock, 1999).

Nessa concepção, a subjetividade, aspecto fundamental no desenvolvimento da pesquisa, é vista como um campo psicológico que abarca os sentidos (carregados de afeto) que o sujeito atribui às significações culturais por ele apropriadas ao longo de sua vida. Como processo dinâmico e contínuo de construção, a subjetividade se constitui por meio de situações de intersubjetividade, nas quais o sujeito, ao contribuir com a construção de significações culturais, transforma a natureza ao mesmo tempo em que 
é transformado por ela. Dessa forma, a passagem do nível interpsicológico (internalização e significação do material cultural na relação com o outro) para o intrapsicológico (sentido pessoal atribuído ao material significado culturalmente) envolve, na construção de sujeitos com trajetórias singulares, relações mediadas simbolicamente e que vão além da esfera intelectual (Oliveira, 1992). De acordo com Bock, Furtado e Teixeira (2005), essa subjetividade é

[...] a sintese singular e individual que cada um de nós vai constituindo conforme vamos nos desenvolvendo e vivenciando as experiências da vida social e cultural; é uma síntese que nos identifica, de um lado, por ser única, e nos iguala, de outro lado, na medida em que os elementos que a constituem são experienciados no campo comum da objetividade social. Esta síntese - a subjetividade - é o mundo de ideias, significados e emoções construído internamente pelo sujeito a partir de suas relações sociais, de suas vivências e de sua constituição biológica; é, também, fonte de suas manifestações afetivas e comportamentais. (p. 23)

Em um ensaio de psicologia social, Ciampa (2005) ofereceu-nos um estudo cuidadoso sobre a identidade como metamorfose, isto é, como processo inexorável (implacável e inflexível), no qual, consciente ou não, o sujeito vê-se submetido a transformações contínuas, constituindo sua subjetividade. Reconhecer-se e ser reconhecido pelo outro em sua singularidade torna-se fundamental para seu processo de diferenciação. É um paradoxo que, para esse autor, revela um dos segredos da identidade: "a articulação da diferença e da igualdade" (p. 138). Nesse contexto, "o indivíduo não é mais algo: ele é o que faz” (p. 135).

Atentando para o fazer do educador social, buscamos autores que discutem a construção de identidade profissional em diversas áreas, com especial atenção para a da assistência social, uma vez que a consideramos base norteadora das práticas de assistência. Guima- rães (2004), Giesta (2001) e Allain (2005), discutindo a construção de identidade de professor, e Zimerman (2002), a do magistrado, atribuem à universidade um papel muito importante como campo privilegiado de construção de saberes ao se pensar as aquisições teórico-metodológicas norteadoras da prática.

Nesse sentido, parecem concordar com Guimarães (2004), o qual afirma que o desenvolvimento de competências e habilidades específicas para o bom desempenho de uma função é o requisito fundamental para se "reivindicar a profissionalização de qualquer ocupação” (p. 88). lsso porque, no aspecto psicológico, os cursos de formação contribuem para o desenvolvimento ou fortalecimento da "identidade para si, isto é, da identificação com a profissão, da adesão profissional” (p. 29).

Em uma breve imersão no processo de constituição da identidade de assistente social, encontramos Martinelli (2007) e Simões Neto (2005), cujos estudos oferecem-nos uma reflexão crítica e fecunda para pensarmos a construção de identidade do educador social.

Martinelli (2007) apresentou-nos dois processos de construção de identidade: a identidade atribuída e a identidade construída. Com objetivo de preservação de seu poder hegemônico e controle social, o Estado e a burguesia atribuíram ao Serviço Social uma identidade que, síntese de funções econômicas e ideológicas, levava a uma prática de reprodução das relações sociais de produção capitalista, além de fortalecer a ilusão de que o Estado "nutria um paternal interesse pelo cidadão” (p. 126).

A identidade atribuída do Serviço Social pelo capitalismo e
[...] chancelada pela Igreja Católica [...] descaracterizava sua função essencial en- quanto resposta ao conjunto de problemas que se instauravam como subprodutos do capitalismo, transformando-se em mero apêndice da função econômica, em estraté- gia de domínio de classe. (p. 126) 
Sucumbiam, assim, os principais elementos fundantes de uma consciência política, ou seja,

\section{[...] a consciência das contradições, a práti-} ca politicamente organizada, a identidade de interesses como classe, abrindo espaço para práticas alienadas e alienantes, fazendo com que a profissão de assistente social não ganhasse legitimidade entre os usuários nem valorização, seja na consciência popular, seja, paradoxalmente, na consciência de muitos de seus agentes. (p. 143)

Dessa maneira, Martinelli (2007) trouxenos como contribuição o fato de que uma identidade profissional pode estar submetida aos caprichos de uma ordem alienante, ocultando em seu discurso de mudança as estratégias de controle social. Ao atuar a serviço de um controle social favorecedor da reificação de seus agentes e das pessoas às quais destina suas ações, essa identidade caracteriza-se como identidade atribuída. Isso significa dizer que uma prática de assistência social pode estar submetida à função econômica (burguesia, Estado, lgreja), "substituindo o educativo pelo assistencial e transformando a crítica em resignação, em passiva aceitação" (p. 158).

Simões Neto (2005), ao estudar a religião no Serviço Social, diz que a gênese das práticas da assistência social no Brasil acontece a partir da iniciativa da Igreja Católica, que tem como pressuposto a ação voluntária exercida na fé e na esperança, preconizando a igualdade de condições entre as pessoas como princípio básico para se estabelecer uma sociedade justa. Assim, os assistentes sociais na nossa realidade entendem a ajuda social "[...] como forma verticalizada de utilização do poder profissional, para a correção das injustiças sociais, não na sua fonte, mas nos seus resultados" (p. 102).

Nesse estudo, Simões Neta (2005) constatou que o desejo de ajuda, abarcado pelo caráter religioso, não é privilégio do Serviço Social. Em maior ou menor grau, outras profissões apresentam essa mesma característica, tan- to na escolha quanto na progressão de sua prática: Pedagogia, Enfermagem, Ciências Sociais, Ciências Contábeis, por exemplo. 0 autor destacou, no entanto, que "o caráter interventivo das profissões da assistência e da Pedagogia dá a estas um caráter missionário [...] que, por sua vez, [...] supera o desprestígio que as carreiras possam ter" (p. 115). Um desprestígio retratado, em certo sentido, pelos baixos (ou modestos) salários e falta de estrutura para um bom desempenho da função. Fala, ainda, em certo

\section{[...] imobilismo metodológico do assistente} social, o que cria uma lacuna para que recursos como a intuição e o senso comum, aliados a outros procedimentos, estranhos às finalidades profissionais, sejam utilizados no cotidiano de trabalho. (p. 152)

Outro aspecto de extrema importância para pensarmos a construção de uma identidade é a autonomia das escolhas. Nesse sentido, Sawaia (2002), refletindo o uso do referencial da identidade na dialética inclusão/exclusão, observou que a autonomia das escolhas pode ser favorecida com o enfraquecimento da tradição, desde que acompanhada de atitude reflexiva. 0 impedimento da reflexão pode causar "sofrimento de diversas ordens e mecanismos defensivos, fundamentalistas e 'apartheid', sendo um dos mais comuns a busca de parâmetros fixos de identidade" (p. 121). Há aqui uma tensão entre as concepções

[...] permanência/unicidade e transformação/ multiplicidade que permite conceber a identidade como 'identificações em curso', isto é, identidade que, ao mesmo tempo que se transforma, afirma um 'modo de ser'. (p. 121)

Ainda sobre a escolha, ao considerar a construção de identidade como processo de constantes negociações que vão muito além de uma universalidade homogeneizante, Melucci (2004) diz que nada é definitivamente perdido nem definitivamente adquirido: "[...] portanto, 
aquela que se abre é uma experiência de si, na qual a provisoriedade e a reversibilidade tornam-se constitutivas da experiência” (p. 68).

A construção de uma identidade profissional implica, portanto, um processo de produção de novas relações sociais, o enfrentamento das adversidades, o desenvolvimento de competências e habilidades específicas para o exercício da prática, contribuindo, dessa maneira, para construção de novos saberes. Implica, ainda, considerando o exercício da prática como uma das formas de relação do sujeito com o meio no qual está inserido e no qual intervém, o olhar do outro, o julgamento do outro e a clareza de que o que se busca é o reconhecimento pelo seu fazer e não pelo seu ser (Lima; Hopper; Souza-Lima, 2004).

\section{A metodologia desenvolvida}

Escolhemos a pesquisa qualitativa para que tivéssemos a possibilidade de um olhar mais aprofundado sobre os aspectos objetivos e subjetivos que compõem as relações sociais e a constituição da subjetividade do educador social. Elaboramos um instrumento com três partes: a primeira, um questionário com perguntas que abarcavam a identificação do sujeito, formação acadêmica, condição socioeconômica e aspectos relevantes de sua prática profissional. Assim, levantamos o perfil socioeconômico e cultural desses educadores, bem como aspectos qualitativos de sua prática cotidiana. Na segunda parte, solicitamos aos sujeitos que escrevessem duas cartas: a primeira para um colega de faculdade a quem não viam há algum tempo, contando a sua experiência como educador social. A outra, para uma pessoa que vive em situação de risco social, expondo-lhe o trabalho que desenvolvem, com a finalidade de preparar sua entrada na comunidade. Buscamos, dessa forma, identificar de que lugar o educador social fala quando se refere à sua prática cotidiana, tendo como interlocutor, por um lado, a população atendida e, por outro, alguém que supostamente esteja em uma situação semelhante à sua, de inclusão social, de formação universitária e, pelo menos em parte, de atuação profissional. Por fim, na terceira parte, havia espaço para que os sujeitos pudessem manifestar alguma informação, observação ou comentário que considerassem necessários acrescentar ou reforçar, caso não tivessem sido contemplados nas etapas anteriores.

Com esse instrumento, tínhamos o objetivo de contemplar o universo simbólico dos conteúdos relacionais e culturais significados por quinze educadores sociais de áreas de formação universitária diversas (Psicologia, Serviço Social, Pedagogia, Ciências Sociais, Artes Plásticas, Ciências Contábeis e Jornalismo), vinculados a Organizações Não Governamentais - ONGs - e/ou outras instituições de atenção à população referida, desenvolvendo trabalho socioeducativo na cidade de São Paulo, com o caráter "profissional” (remunerados) e não voluntário.

Para mantermos em sigilo o nome real de cada sujeito, utilizamos, inspirados na forma de nomeação das personagens do romance Ensaio sobre a Cegueira, de Saramago (2001)', pseudônimos de acordo com a formação universitária dos participantes. Quando da mesma área de formação, adjetivamos esses nomes a partir de algum aspecto marcante de cada discurso: o psicólogo do tempo; a assistente social do "Ufa!!!" etc.

A reflexão metodológica contou, principalmente, com estudos de Franco (2003); Aguiar (2001); Rosa e Adriani (2002), além de Melucci (2005) e colaboradores que têm direcionado um olhar para os aspectos contemporâneos da pesquisa qualitativa desenvolvida no campo social.

\section{Sobre a organização dos dados e da análise}

Para este artigo, apresentamos a caracterização desses educadores, mediante quadro demonstrativo (Tabela 1). Destacamos também os motivos da escolha por exercer a função de

1. Nesse romance, Saramago retrata com extrema pertinência alguns arranjos e desarranjos da vida social, a partir de certa epidemia: a cegueira branca. Apresenta-nos suas personagens, nomeadas de forma peculiar: o médico; a mulher do médico; a rapariga dos óculos escuros etc. 
Tabela 1: Sintese geral dos educadores sociais sujeitos desta pesquisa.

\begin{tabular}{|c|c|c|c|c|c|c|c|c|c|}
\hline \multirow[t]{2}{*}{ Média idade } & \multicolumn{2}{|c|}{ Estado civil } & \multirow[t]{2}{*}{ Casa própria } & \multirow{2}{*}{$\begin{array}{l}\text { Média da renda } \\
\text { familiar }\end{array}$} & \multicolumn{2}{|c|}{$\begin{array}{c}\text { Tempo como } \\
\text { Educador Social }\end{array}$} & \multicolumn{2}{|c|}{$\begin{array}{c}\text { Carga horária } \\
\text { semanal }\end{array}$} & \multirow{2}{*}{$\begin{array}{c}\text { Não satisfeito } \\
\text { com salário }\end{array}$} \\
\hline & casado & solteiro & & & $d e$ & $a$ & $d e$ & $a$ & \\
\hline 33 anos & 05 & 09 & 12 & $\mathrm{R} \$ 3.270,00$ & 02 anos & 20 anos & $08 \mathrm{~h}$ & $44 \mathrm{~h}$ & 12 \\
\hline
\end{tabular}

educador social, alguns aspectos revelados na análise sobre a satisfação e a insatisfação com a prática, bem como o tempo que pretendem continuar na função. Por fim, consideramos alguns trechos das cartas, ratificando constatações e revelando novas manifestações. Essa forma de nortear nossa pesquisa se justifica porque o que está implícito, de algum modo, aflora nas entrelinhas do texto e, por isso mesmo, entre o que o educador social diz de si e de sua prática e o que cala, há o lugar por onde deixa revelar-se em sua subjetividade.

\section{A escolha}

Em relação ao questionamento sobre o que levou esses sujeitos a serem educadores sociais, evidenciou-se inicialmente a possibilidade de trabalhar na área de sua formação profissional. De acordo com suas respostas, essa possibilidade originou-se no período de formação universitária, despertando em alguns o interesse e o "gosto" por dar continuidade ao trabalho desenvolvido. Há educadores que manifestaram identificação com causas sociais e indignação com as desigualdades e injustiças sociais: na "motivação idealista de desejar um mundo melhor" (o psicólogo do tempo); "indignação diante das diferenças sociais” (a assistente social do "Ufa!!!”). Expressaram também a crença de que a educação é primordial para que haja mudanças e que, no exercício da prática, é preciso considerar o "[...] indivíduo na sua totalidade e a partir da realidade em que está inserido" (o cientista social).

Subjacente aos discursos de oportunidade à motivação idealista, à paixão pelo ofício, à indignação com as desigualdades sociais, à flexibilidade de atuação permeando essa escolha, pareceu-nos que esses educadores acataram a influência de valores, inclusive os religi- osos. Estes se expressaram na prática, muitas vezes, como veremos ao longo da análise, "de forma independente da consciência que se tenha deles" (Simões Neto, 2005, p. 171), como condição essencial para o desenvolvimento de um trabalho que, frequentemente, beira o assistencialismo.

\section{Prática cotidiana: satisfação $x$ insatisfação}

Questionados sobre o que os faz sentirem-se satisfeitos na prática cotidiana, esses educadores apontaram para o fato de que suas intervenções propiciam uma melhora na qualidade de vida das pessoas por eles atendidas. Desse modo, fazem uso da formação profissional e ainda adquirem aprendizados nas relações estabelecidas no desempenho de sua função. Há, talvez, o sentido de continuidade (contrapondo à descontinuidade anunciada dos programas sociais), de ampliação dessa experiência, agraciada pelas manifestações de carinho, gestos, palavras verbalizadas e escritas, registrando um sentimento de gratidão por parte daqueles que são beneficiados pelo trabalho desenvolvido: "[...] o retorno das famílias. Ex: um sorriso, um obrigado você me ajudou muito [...]" (a pedagoga das famílias).

Constatamos que esses educadores sociais também se beneficiam de suas intervenções, como nos revelou a assistente social das famílias, ao dizer: "[...] assim como a constatação da melhora da qualidade de vida desse mesmo público e minha também". Mesmo que aparentemente pequenas, essas mudanças, assim como as manifestações de agradecimento das pessoas atendidas, apresentam um valor extremamente significativo para a autoestima desses educadores. 0 retorno que nos parece pouco, para eles, muito provavelmente, tem sido o 
mínimo suficiente para não desistirem da motivação idealista, do desejo de ajuda, da busca por justiça social.

Em relação à insatisfação com a prática, o salário ganhou destaque nas manifestações dos educadores sociais. Geralmente baixo, foi responsabilizado por não permitir ao educador usufruir de um padrão de vida satisfatório. A assistente social dos oprimidos, por exemplo, mesmo ganhando acima da média, diz que o salário é baixo em relação à amplitude e às exigências do trabalho ao se pensar "[...] os aspectos emocionais e subjetivos que ele requer do profissional. [...] o que revela a desvalorização do profissional e o descaso que é tratada a 'questão social' no Brasil, especialmente no estado de São Paulo”. Já, para o psicólogo do tempo, “[...] o educador social é pessimamente remunerado. 0 mercado não diferencia o educador social com ou sem nível superior".

Os baixos salários são considerados, ainda, empecilho para o investimento na formação educacional e "profissional". Apesar da necessidade evidenciada, grande parte desses educadores limitou-se à formação de base, não investindo no desenvolvimento de competências para o exercício do trabalho socioeducativo. lsso porque "[...] o salário destinado ao profissional mal permite a quitação de suas despesas mensais [...]” (a psicóloga do aprender).

Embora três educadoras sociais tenham se declarado satisfeitas com o salário, consideramos que isso se deve à comparação com os baixos salários do mercado. Um exemplo é o que diz a artista plástica que, além dessa comparação, também aponta para a instabilidade da função ao dizer:

[...] conheço poucos profissionais que atuam com educação não formal que recebam salário equivalente. Porém procuro estar alerta: essa área é muito instável e um salário razoável hoje pode não existir amanhã.

Outro fator de insatisfação é a descontinuidade dos programas sociais. Abruptamente e de forma verticalizada, convênios entre Estado e as instituições que implantam e desenvolvem esses programas são cancelados. Assim, grande parte deles é extinta antes de completar o prazo determinado de duração, desconsiderando o planejamento, o investimento (tanto material quanto afetivo) na e das pessoas envolvidas, resultando na insegurança e no desconforto de um trabalho iniciado, mas nem sempre concluído. 0 que, de certa forma, retrata um aspecto que nos pareceu ser a espinha dorsal da insatisfação: a falta.

Essa falta de condições materiais, físicas e de conhecimento reforça uma situação que exigiu um olhar cuidadoso. Esse educador nos mostrou que sua condição de trabalho é precária, denunciando que sua condição de vida talvez não esteja distante da encontrada nesse território. A falta, então, concebida como empecilho para o desenvolvimento do trabalho socioeducativo, levou, muitas vezes, à inércia e, inevitavelmente, à queixa.

Pensando Melucci (2004), essa falta é orientada para determinados objetos que são simbolicamente construídos pelo universo da comunicação publicitária, pela informação, pelo mercado e, inevitavelmente, pelas redes sociais às quais pertencemos também simbolicamente. Por isso, a importância de "[...] aprender a abrir e fechar, a participar e subtrair-se ao fluxo das mensagens, à chamada dos possíveis e às exigências dos afetos", descobrindo, dessa maneira, "[...] um ritmo de entrada e de saída das relações que nos permita dar e receber informações sem perder o sentido da comunicação e sem que se esvazie o ato de comunicar" ( $p$. 69). 0 que possibilitaria, assim acreditamos, a sustentação do sentimento de indignação frente às mazelas da vida.

Caberia, então, ao educador social a responsabilidade por uma escolha que evidencia o lugar em que se coloca diante das situações de adversidades. Pela queixa, a falta leva a uma mesmice apaziguadora de descontentamentos. Pela possibilidade de ação, a falta desperta inquietudes, exigindo a busca por processos de 
mudanças que, em certo sentido, contemplam a noção de identidade como metamorfose; metamorfose como vida (Ciampa, 2005).

Outro aspecto levantado no discurso dos educadores, dando sequência à sua insatisfação, foi o da discrepância entre os interesses políticos e a prática em si, além da burocracia e do não respeito ao tempo do outro, o que leva ao "atropelo do processo, do trabalho" (o psicólogo do tempo). Apontaram que decisões políticas são tomadas por pessoas que desconhecem a realidade da prática, desconsiderando a experiência daqueles que estão diretamente envolvidos no processo de transformação. Atualizaram, assim, a ideia de identidade atribuída (Martinelli, 2007), que leva a uma prática cuja finalidade é a de manter o controle hegemônico sobre a população menos privilegiada.

Entre os baixos salários, as condições precárias de trabalho, o não investimento na capacitação e qualificação profissional, a burocracia, os problemas de comunicação, o não reconhecimento do outro e, muitas vezes, a do próprio educador, encontramos na fala da assistente social dos oprimidos (talvez como porta-voz desses educadores sociais), o que pensamos representar um aspecto subjacente aos discursos apresentados. Latente ao conteúdo manifesto e, portanto, fundamental para nossa análise, destacamos o sentimento de impotência permeando as ações interventivas constituídas na e pela falta.

Falta de preparo dos profissionais; o desmonte/falta de políticas públicas de assistência social; a falta de recursos públicos/ privados; a falta de comunicação entre os setores que atuam na área social; a falência da educação e saúde pública; a demagogia do terceiro setor. Tudo isso me traz insatisfação, desgaste, desânimo e muitas vezes me faz pensar até que ponto o meu trabalho tem significado/valor. Sinto-me impotente.

Sentir-se impotente é sentir-se impossibilitado de realizar, de fazer algo considerado importante para uma possivel transformação. Assim, o sentimento de impotência manifestado pela assistente social dos oprimidos talvez esteja retratando que a motivação inicial, a vontade e o desejo, compondo o campo dos valores e afetos (Simões Neto, 2005), diluem-se na prática cotidiana do educador social. 0 que, de certa forma, ecoa nas palavras de P. Ayerbe (apud Romans; Petrus; Trilla, 2003) quando questiona se a ação do educador social tem sido transformadora ou apenas uma espécie de intervenção

\section{[...] suavizadora das contradições existentes no seio da sociedade, camuflando e ocultan- do as desigualdades e as injustiças sociais, tentando simplesmente adaptar o indivíduo às coordenadas sociais existentes. (p. 131)}

\section{O tempo}

Questionados por quanto tempo pretendem trabalhar como educadores sociais, a indeterminação ganhou destaque em suas falas. Há a imprecisão motivada, principalmente, pelo fato de que "[...] o trabalho na área social é muito incerto, desgastante e mal remunerado" (o psicólogo do tempo). No entanto, alguns educadores, referindo-se ao gosto pelo trabaIho, à motivação e ao prazer, afirmam a pretensão de atuar enquanto acreditarem que suas ações possam trazer bons resultados.

Outros declararam que exercerão o trabalho como educador social por muito tempo, "por toda a vida", porque "[...] o ato de ensinar é um dom divino que Deus entrega na mão de quem ele acredita ser capaz para desenvolver esta habilidade [...]" (a pedagoga das crianças). Há, aqui, a ideia de "missão" como atribuição divina, ratificando, mais uma vez, as constatações de Simões Neto (2005), revelando-nos que as práticas assistenciais são, em maior ou menor grau, permeadas por valores religiosos.

Encontramos ainda educadores sociais objetivamente indeterminados: "Não sei, não escolhi essa profissão" (a artista plástica); "Quanto tempo for necessário" (a pedagoga das famílias); "Hoje, eu penso que para sempre. Amanhã, eu não 
sei..." (a assistente social do "Ufa!!!"). Complementando, entre dúvidas, motivações, prazer, identificações, oportunidades, pensamos que a assistente social dos oprimidos pode ser considerada, outra vez, porta-voz desses educadores. Apresenta-nos o dilema mudar $\mathrm{x}$ prosseguir como fator importante que parece permear as escolhas em relação ao tempo de dedicação nessa função. A grande dificuldade está, talvez, no responsabilizar-se por essas escolhas: o que fazer?

É difícil!!! Mas se eu pudesse escolher, eu optaria por exercer outra atividade profissional que fosse bem remunerada como na área comercial. Paralelamente desenvolveria atividades lúdicas com pessoas, crianças, adultos, adolescentes etc., em situação de vulnerabilidade social. Estou cansada de encarar tanto sofrimento cotidianamente, tanta desesperança... PS: às vezes, sinto-me num dilema mudar $\mathrm{x}$ prosseguir...

A partir do exposto, alguns questionamentos tornaram-se inevitáveis para pensarmos a construção de identidade do educador social: será que esses educadores, assim como a população atendida, também estão à espera de um "salvador", isto é, alguém que os tire dessa situação pouco favorável para o desenvolvimento de seu trabalho, oferecendo-lhes o mínimo de dignidade e respeito? Mesmo recebendo baixos salários, a vivência da instabilidade e tudo mais que acompanha a sua prática, há o sentir-se menos excluído do que os excluídos com os quais desenvolve seu trabalho, uma vez que se coloca na posição de "ajudador", de assistencialista? Há, de certa forma, por parte desses educadores, o apoiar e o desenvolver práticas assistencialistas e verticalizadas, assegurando determinada importância de sua função, ou seja, enquanto houver o excluído, haverá a necessidade de um interventor para o processo de inclusão?

\section{As cartas}

Nas cartas a um amigo da faculdade, destacamos as queixas frequentes em relação aos baixos salários e à elevada carga horária de trabalho, além das condições precárias para o exercício da prática, caracterizando a falta. Houve também a descontinuidade, principalmente dos programas sociais, apontando para "instabilidade no emprego", como nos diz o cientista social, referindo-se ao projeto no qual estava engajado: “[...] é um trabalho que tem tempo certo para 'nascer e morrer'. Infelizmente as oportunidades voltadas a minha área possuem este perfil”. No entanto, o fato de esse trabalho ter um tempo determinado para "nascer e morrer", não necessariamente retrata uma descontinuidade. 0 que a caracteriza é, justamente, a não concretização desse tempo, quando, muitas vezes, sem aviso prévio, o convênio é verticalmente cancelado antes do previsto ou não renovado, deixando a cargo desses educadores as explicações e justificativas para a população atendida.

Outro aspecto que chamou a atenção foi a forma como a assistente social dos oprimidos referiu-se ao período em que atuou na FEBEM, onde os recursos eram precários e essa experiência trouxe-lhe consequências afetivas: "[...] me tornei uma pessoa mais dura afetivamente, quase não choro [...]". Há certa naturalização dessa experiência legitimada pelo outro, no caso específico por sua terapeuta, quando lhe diz que "[...] esse fenômeno é comum com as pessoas que trabalham com o que eu trabalho [...]". Parece reforçar, assim, um sentimento de resignação e sofrimento que pode ser compartilhado com o discurso da jornalista que diz não ser fácil lidar

[...] com histórias de vida tão tristes, situações tão miseráveis ou tão complexas que dá nó na cabeça. Vivo me questionando se meu trabalho é importante, se faz alguma diferença.

As cartas também nos apresentaram algumas das atribuições desses educadores sociais, sintetizadas nas palavras da assistente social do "Ufa!!!", apontando para uma situação que nos parece ser muito mais do que esses educadores possam dar conta. Não é de se admirar o des- 
fecho da citação a seguir, ecoando, de certa maneira, as falas dos educadores sociais:

\section{[...] neste programa, atendemos famílias em} alto grau de vulnerabilidade social através de grupos socioeducativos, quinzenais, com duração de $1 \mathrm{~h}$ e 30 '. Mas não é só isso: eu planejo, executo e adapto dinâmicas voltadas para a realidade das famílias atendidas, faço visitas domiciliares, relatórios, acompanhamento de casos específicos, atendimento individual e familiar, entrevistas, estudo social, encaminhamentos, orientações, articulo a rede comunitária da região para auxiliar a implementação e o planejamento do trabalho socioeducativo. Também trabalho com uma equipe multidisciplinar e participo de seminários, palestras etc., além de sistematizar os dados acerca do trabalho desenvolvido. Ufa!!! É muito trabalho [...].

Apesar das adversidades enfrentadas na prática e do sofrimento que emerge a partir delas, constatamos que há algumas satisfações dos educadores sociais no desenvolvimento do trabalho socioeducativo, demonstrando um olhar prospectivo para o enfrentamento dessa situação. Como exemplo, mostramos a trajetória da assistente social satisfeita que, embora se assemelhe a de outros educadores, diferencia-se ao não se contentar com o descontentamento que parece permear a prática cotidiana, sustentando a queixa. Ao contrário, investiu e continua investindo em sua formação. Como resultado, “[...] atualmente estou responsável por coordenar ações junto a uma equipe de educadores recémcontratados". 0 verbo estar, na fala dessa educadora, sugere-nos possibilidades de mudança mediante ações inovadoras, ressignificações e construção de novos sentidos, de novos olhares sustentadores do campo das motivações, portanto, metamorfose (Ciampa, 2005).

Nas cartas destinadas a uma pessoa que vive em situação de risco e exclusão social, alguns educadores sociais destacaram sua formação profissional e, em seguida, sua função. Isso nos levou a pensar que se apresentar como Psicólogo, Assistente Social, Cientista Social etc. represente certo status e o sentido de afiliação identitária (Semprini, 1999) com a formação profissional, dando-lhes provavelmente uma base de sustentação e norteamento para a função de educador social.

Outro dado relevante implícito nas cartas de vários educadores, mas explicitamente posto na carta da pedagoga das crianças, é o da religiosidade, apontando como um dos caminhos da salvação o "caminho do Senhor". Subjacente à sua escrita manifesta, parece desresponsabilizar-se de sua atuação como educadora social e, ainda, destituir da Senhora "Flor de Maio" (destinatária da carta) sua parcela de responsabilidade frente ao vivido. A religião se materializou nas palavras dessa educadora social como possibilidade iminente de resolução do problema, comprometendo sua reflexão e, consequentemente, sua capacidade criativa, levando-a à mesmice. Nesse sentido, entre o divino e sua prática cotidiana, talvez lhe escape o princípio ético da distância ótima, ou seja, manter uma "[...] distância que permita garantir a conjugação equilibrada entre racionalidade, sensibilidade e serenidade" (Carvalho; Baptista, 2004, p. 93), certa imparcialidade na sua atuação, capacidade de escuta, criatividade, reflexão (Romans; Petrus; Trilla, 2003), além da clareza de que o que the serve não necessariamente cabe ao outro.

$\mathrm{Na}$ última parte do instrumento, destacamos a artista plástica que, atuando com jovens da periferia e de uma escola particular que atende "parte da elite paulistana", observou que, contrariamente aos jovens da "elite paulistana", há nos jovens da periferia "[...] um incentivo a que se qualifiquem, de modo homogeneizante, para servir". Essa educadora mostrou-nos a visão estereotipada que a sociedade tem da desigualdade social, reforçando a ideia de que "o pobre nasceu para servir e o rico para liderar". Ou, ainda, revelou-nos como essa realidade tem se apresentado, atualizando a fala de Sposito e Corrochano (2005) quando dizem que as propostas educativas dos programas sociais, principalmente relacionadas à precariedade material e à baixa formação técnica, podem favorecer e 
[...] acentuar [...] mecanismos perversos de reprodução de uma base humana e material precária, [...] reiterando a ideia de que não é preciso oferecer muito aos pobres. (p. 17)

Já a assistente social satisfeita fez uma sintese reflexiva e questionadora de sua vivência como educadora social. Disse que a falta parece preponderar nas relações entre o Estado e aqueles que buscam algum tipo de parceria, de convênio com ele (as instituições e os educadores sociais, a sociedade civil etc.), levando-os, muitas vezes, a se colocarem na mesma posição do público que atendem (pareceu referir-se aqui a certa "mendicância"). Apontou o Estado como maior responsável pela manutenção dessa situação de precariedade social, porque “[...] repassa recursos mínimos com exigências máximas para as organizações e fica omisso de seu compromisso".

Paradoxalmente, assim nos parece, esses mesmos educadores (assim como a população por eles atendida) consideram o Estado um algoz e um possível "salvador": algoz, ao não se sentirem respaldados por "Ele" em suas necessidades elementares; "salvador", nas promessas de colocar em prática projetos sociais, mediante os programas que, por um lado, evidenciam a oportunidade de emprego e, por outro, alimentam a esperança de ser assistido.

Chamamos a atenção para o fato de que, independentemente do aspecto que prepondere, parece-nos que tanto a artista plástica como a assistente social satisfeita espelham, em seus discursos, o lugar e os sentimentos da maioria dos educadores sociais: impotência, frustração, desvalorização, contemplando a resignação diante dessa realidade desfavorável à dignidade humana.

Como o sentimento de resignação implica a renúncia a algo, a submissão aos sofrimentos da vida, o conformismo (Dejours, 2001), impossibilitando a construção de ações inovadoras ou simplesmente propiciadoras de alguma transformação, temos justificada, novamente, a noção de identidade atribuída (Martinelli, 2007). Isso, de certa forma, leva-nos a pensar que, paradoxalmente, em um campo de traba-
Iho onde parece caber tudo, pouco tem sido feito no sentido de consolidar alguma mudança. Um pouco respaldado, com certa apatia, pela evidência da falta, da descontinuidade.

\section{Considerações finais}

Das características de identidade que esses educadores vêm construindo em sua prática cotidiana, destacamos a insatisfação, a frustração, o não se sentir reconhecido, o não se sentir respeitado como principais aspectos constituintes dos sentimentos de desvalorização e de impotência que se apresentam como síntese de um discurso mobilizado pela falta e pela descontinuidade, sustentando a queixa instaurada no exercício dessa prática.

Se, em um primeiro momento, o educador social tem a indignação como motivação para desenvolver um trabalho transformador, logo depois parece não a sustentar, apropriando-se de um discurso de resignação semelhante ao da população atendida. 0 que nos remete à ideia de que, subjacente ao discurso de responsabilidade, inspirado talvez numa aparente ingenuidade, esse educador esforça-se para acreditar que sua intervenção o diferencia da condição de precariedade vivida pelo outro. lsso o coloca à margem da criticidade, levando-o a sustentar um papel de mediador para a imposição das propostas de intervenção oriundas, principalmente, de projetos e programas sociais criados pelo Estado, atualizando, dessa maneira, ações verticalizadas.

$\mathrm{Na}$ prática, o fato de não haver uma metodologia específica para o desenvolvimento do trabalho socioeducativo, o que deveria ser um aliado à criatividade, ao olhar prospectivo e à autonomia nas ações, parece despertar no educador social um sentimento de desamparo frente às adversidades cotidianas. A consequência direta disso é que passa a respaldar suas intervenções no conhecimento acadêmico adquirido em sua formação universitária, utilizando-se de metodologias de trabalho já prontas e, muitas vezes, pouco adequadas para o exercício de uma prática que requer construção. 
Não é de se admirar que esses educadores sociais evidenciem, diante dessa realidade, a necessidade de aprimorar sua formação para o desenvolvimento do trabalho socioeducativo, mediante certa insistência em denunciar a falta de investimentos, qualificação, especialização, capacitação, supervisão etc. Essa manifestação revela-nos que há uma perspectiva muito boa para que esses educadores se reconheçam e possam ser reconhecidos em suas diferenças, em suas potencialidades, uma vez conscientizados da necessidade de respaldo de algumas carências.

Devemos considerar, entretanto, um risco subjacente nesse discurso denunciante. Carente de afiliação identitária profissional de educador social, o apelo por cursos de qualificação talvez esteja a serviço da busca por destrezas que possam se tornar técnicas a serem simplesmente aplicadas na prática, eximindo-se da responsabilidade de construção, o que justificaria o seu fazer pouco efetivo. Daí a necessidade da criação de um campo de discussão, de reflexão e de construção contínua entre as práticas de intervenção já instauradas e a contribuição das diferentes áreas do conhecimento, construindo e aprimorando constantemente um novo saber capaz de respaldar as demandas desses sujeitos e suportar as inquietações tão necessárias para a manifestação de ações criativas e transformadoras, em detrimento de um suposto saber que beira ao senso comum e, não raramente, de uma forma velada, que se vê carregado de religiosidade.

Nesse sentido, apontamos a universidade como campo de discussão, reflexão e formação profissional para esse sujeito, desde que seus gestores e mediadores estejam motivados para estabelecer uma relação de construção mútua com os sujeitos experientes (ou não) da prática de educador social, balizada por uma ética deontológica, assegurando-lhes um caminho e um processo para afiliação identitária profissional de educador social. 1sso, em detrimento do instrucionismo que imbeciliza (Demo, 2007) e da construção de manuais de instrução para uma prática que exige olhar pros- pectivo, criatividade, polivalência, otimismo, realismo, profissionalidade etc.

A profissionalização do educador social, portanto, é um passo que consideramos fundamental para que se possa assegurar, no mínimo, o sentido de responsabilidade pelas próprias escolhas. Isso porque seu discurso manifesto, calcado na falta e na queixa, talvez esteja mascarando o conforto da comodidade e da não responsabilidade de uma "identidade atribuída". Dessa maneira, a prática, que muitas vezes é concebida como favor e não como direito, só poderá ser ressignificada quando esse sujeito, de fato, reivindicar e fazer valer os seus próprios direitos, dentre os quais o de ter condições favoráveis de trabalho, melhores salários, espaço de formação contínua, de supervisão profissional, de escuta e de acolhimento, tornando-se responsável pelo processo de construção de sua identidade de educador social.

0 processo de construção de identidade implica, assim, um movimento de construção e desconstrução constante, norteado pela ressignificação dos sentidos que o sujeito atribui ao seu fazer, atentando para o modo como se enxerga na realidade na qual intervém e como enxerga essa mesma realidade. Enquanto seu olhar para o pobre, a favela, a comunidade e, muitas vezes, a instituição onde trabalha espelhar um quarto de despejo cheio de trastes velhos (Jesus, 1993), pouco (ou nada) poderá, de fato, ser realizado.

Este estudo, portanto, revelou-nos que o educador social vê-se do mesmo modo como vê as pessoas a quem assiste e a favela como extensão de si. Logo, não há condições de mudanças. É preciso, então, que enxergue o real sentido que tem atribuído à significação dessa realidade e ao seu fazer, revelando a si mesmo aspectos de sua subjetividade, de sua singularidade. Isso, certamente, lhe abriria possibilidades de ressignificação e de diferenciação em relação às pessoas por ele atendidas. Nesse sentido, há a chance de destituir, assim acreditamos, a religião, o favor, a queixa, a missão, a resignação, a impotência, a desvalorização... como álibis da sua desesperança. 


\section{Referências bibliográficas}

AGUIAR, W. M. J. A pesquisa em psicologia sócio-histórica: contribuições para o debate metodológico. In: BOCK, A. M. B; GONÇALVES, M. G. M; FURTADO, 0. (Orgs.). Psicologia sócio-histórica: uma perspectiva crítica em psicologia. São Paulo: Cortez, 2001. p. 129-140.

ALLAIN, L. R. Ser professor: o papel dos dilemas na construção da identidade profissional. São Paulo: Annablume; Belo Horizonte: FUMEC, 2005.

BOCK, A. M. B. Aventuras do Barão de Münchhausen na psicologia. São Paulo: EDUC; Cortez, 1999.

BOCK, A. M. B.; FURTADO, 0.; TEIXEIRA, M. de L. T. Psicologias: uma introdução ao estudo de psicologia. 13. ed. São Paulo: Saraiva, 2005.

CARVALHO, A. D. de; BAPTISTA, I. Educação social: fundamentos e estratégias. Porto, Portugal: Porto Editora, 2004. Coleção Educação e Trabalho Social.

CIAMPA, A. da C. A estória do Severino e a história da Severina. São Paulo: Brasiliense, 2005.

DEJOURS, C. A banalização da injustiça social. Tradução de Luiz Alberto Monjardim. 4. ed. Rio de Janeiro: Editora FGV, 2001.

DEMO, P. Estudar não é ter aulas. Disponível em: <http://www.quadrante.com.br/Pages/serviços02.asp?id=290\&categoria=Educacao > . Acesso em: 06 nov. 2007.

FRANCO, M. L. P. B. Análise do conteúdo. Brasília: Plano, 2003.

GIESTA, N. C. Cotidiano escolar e formação reflexiva do professor: moda ou valorização do saber docente? Araraquara: JM, 2001.

GONÇALVES FILHO, J. M. Humilhação social: um problema político em psicologia. Psicologia USP, São Paulo, v. 9, n. 2, p. 11-67, 1998.

GUIMARÃES, V. S. Formação de professores: saberes, identidade e profissão. Campinas: Papirus, 2004.

JESUS, C. M. de. Quarto de despejo: diário de uma favelada. São Paulo: Ática, 1993.

KAHHALE, E. M. P. (Org.). A diversidade da psicologia: uma construção teórica. São Paulo: Cortez, 2002.

KOGA, D. Medidas de cidades: entre territórios de vida e territórios vividos. São Paulo: Cortez, 2003.

LIMA, S. M. M. de; HOPFER, K. R.; SOUZA-LIMA, J. E. de. Complementaridade entre racionalidades na construção da identidade profissional. RAE-eletrônica, v. 3, n. 2, art. 19. Disponível em: <http://www.rae.com.br/eletronica/index.cfm?FuseAction=Artigo\&Seção $=$ GESTREL\&Volume=3\&Numero=2\&Ano=2004>. Acesso em: jul./dez.2004.

MARTINELLI, M. L. Serviço social: identidade e alienação. 11. ed. São Paulo: Cortez, 2007.

MELUCCI, A. 0 jogo do EU: a mudança de si em uma sociedade global. São Leopoldo: Editora Unisinos, 2004.

Por uma sociologia reflexiva: pesquisa qualitativa e cultura. Tradução de Maria do Carmo Alves do Bomfim. Petrópolis: Vozes, 2005.

MIOTO, R. C. T. Ações socioeducativas em programas de transferência de renda. (Texto 4). In: WANDERELY, M. B.; OLIVEIRA, I. I. de M. C. (Orgs.). Trabalho com famílias: metodologia e monitoramento. (v. 2). São Paulo: IEE-PUC, 2004. p. 45-51.

MOLON, S. I. Subjetividade e constituição do sujeito em Vygotsky. São Paulo: EDUC; FAPESP, 1999.

OLIVEIRA, M. K. 0 problema da afetividade em Vygotsky. In: LA TAILLE, Y. de; OLIVEIRA, M. K. de; DANTAS, H. Piaget, Vygotsky, Wallon: teorias psicogenéticas em discussão. São Paulo: Summus, 1992. p. 75-84. 
Vygotsky aprendizado e desenvolvimento - um processo sócio-histórico. São Paulo: Scipione, 1997.

ROMANS, M.; PETRUS, A.; TRILLA, J. Profissão: Educador Social. Tradução de Ernani Rosa. Porto alegre: Artmed, 2003.

ROSA, E. Z.; ADRIANI, A. G. P. Psicologia sócio-histórica: uma tentativa de sistematização epistemológica e metodológica. In: KAHHALE, E. M. P. (Org.). A diversidade da psicologia: uma construção teórica. São Paulo: Cortez, 2002. p. 259-288.

SARAMAGO, J. Ensaio sobre a cegueira. São Paulo: Companhia das Letras, 2001.

SAWAIA, B. B. (Org.). As artimanhas da exclusão: análise psicossocial e ética da desigualdade social. 4. ed. Petrópolis: Vozes, 2002.

SEMPRINI, A. Multiculturalismo. Tradução de Laureano Pelegrin. Bauru: EDUSC, 1999.

SILVA, G. H. da. A construção de identidade do educador social na sua prática cotidiana: a pluralidade de um sujeito singular. 2008. Dissertação (Mestrado)- Faculdade de Educação da Universidade de São Paulo, São Paulo, 2008.

SIMÕES NETO, J. P. Assistentes sociais e religião: um estudo Brasil//nglaterra. São Paulo: Cortez, 2005.

SPOSITO, M. P.; CORROCHANO, M. C. The hidden face of the income transference for youths in Brazil. Tempo Soc., São Paulo, v. 17, n. 2, 2005. Disponivel em: <http://www.scielo.br/scielo.php?script=sci_arttext\&pid=S0103-20702005000200007\&lng=en\&nrm=iso> . Acesso em: 13 abr. 2007. Pré-publicação.

VYGOTSKY, L. S. A formação social da mente: 0 desenvolvimento dos processos psicológicos superiores. São Paulo: Martins Fontes, 2003.

ZIMERMAN, D.; COLTRO, A. C. M. (Orgs.). Aspectos psicológicos na prática jurídica. Campinas: Millennium, 2002.

Recebido em 22.05.08

Aprovado em 18.08 .09

Gerson Heidrich da Silva, psicólogo clínico e institucional, mestre em Educação pela FEUSP - área Psicologia e Educação, é professor de Psicologia Geral e Social na Faculdade de Serviço Social - UNISA. 